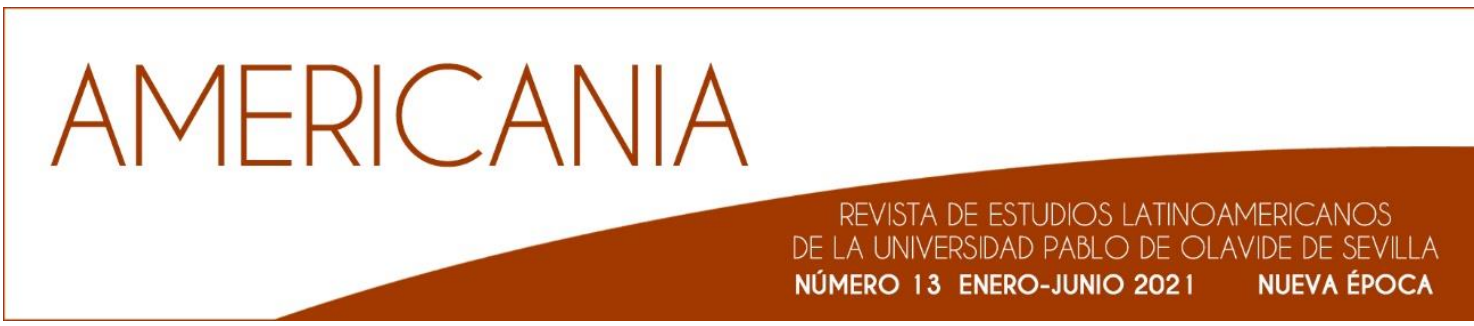

\title{
El plan estratégico de defensa del partido de Arica \\ y sus consecuencias en el mando civil-militar durante los conflictos anglo-francés y anglo-español (1787-1792)
}

\section{Resumen}

La disputa diplomática de Francia contra la alianza anglo-prusiana sobre el conflicto político interno en los Países Bajos, como también la posterior disputa diplomática anglo-española sobre la bahía Nootka-Sound, fueron acontecimientos que obligaron a la corona española a establecer un plan estratégico de defensa imperial preventivo. Para el caso de la Intendencia de Arequipa, sus esfuerzos se concentraron en la movilización de las milicias y en el mejoramiento de la defensa del puerto y ciudad de Arica, dirigido de acuerdo a un plan estratégico-militar elaborado por el intendente Antonio Álvarez y Jiménez. Sin embargo, la ejecución del plan de defensa causó una abierta confrontación entre las autoridades civiles y militares, así como también una lucha en la dirección del mando entre oficiales veteranos y coroneles de milicias. Por estas consecuencias, las reformas militares borbónicas introducidas en el sur peruano, durante la segunda mitad del siglo XVIII, más que una solución a los problemas políticos-militares de seguridad imperial, fueron una causa clave en la escalada de las luchas de poder entre criollos y peninsulares.

\section{Palabras Clave}

Conflicto diplomático anglo-francés - Conflicto diplomático anglo-español - Conflicto civil-militar - Partido de Arica - Estrategia militar

Titulado de historiador por la Universidad de Tarapacá, Chile. Magíster en Historia Militar y Pensamiento Estratégico por la Academia de Guerra del Ejército de Chile. Doctorando en el Programa de Doctorado en Filosofía por la Universidad de Sevilla, España. 


\title{
AMERICANIA
}

REVISTA DE ESTUDIOS LATINOAMERICANOS

DE LA UNIVERSIDAD PABLO DE OLAVIDE DE SEVILLA

NÚMERO 13 ENERO-JUNIO 2021

NUEVA ÉPOCA

\section{The strategic plan of defense of Arica district and its consequences on the civil-military command during the Anglo-French and Anglo- Spanish diplomatic conflicts (1787-1792)}

\begin{abstract}
The diplomatic dispute between France and the Anglo-Prussian Alliance on the Dutch internal political conflict, and the subsequent Anglo-Spanish diplomatic dispute over the Nootka-Sound Bay, were events that forced the Spanish crown to establish a strategic preventive imperial defensive plan. In the case of the Intendancy of Arequipa, its efforts were concentrated in the mobilization of the militias and in the improvement of the defense of the port and city of Arica, directed according to a strategic and tactical defensive plan prepared by the intendant Antonio Álvarez y Jiménez. However, the execution of the defense plan caused an open confrontation between the civilian and military authorities, as also between the veteran official and the militia colonel for the defense command leadership. Because of these consequences, the Bourbon military reforms introduced in Peru, during the second half of the eighteenth century, further polarized political struggle between Creoles and Peninsulares.
\end{abstract}

Key Words

Anglo-French diplomatic conflict - Anglo-Spanish diplomatic conflict - Civil-military conflict - District of Arica - Military strategy 


\section{Introducción}

En 1787 se produjo el conflicto diplomático anglo-francés por la lucha geopolítica de influir en los destinos del gobierno de las Provincias Unidas de los Países Bajos, la que se materializó a través de la asistencia militar directa a las facciones políticas holandesas confrontadas en ese momento. Francia apoyó directamente al partido patriótico holandés, mientras que Inglaterra, en conjunto con Prusia, respaldaron el retorno del Estatúder, antiguo regente que estaba casado con la hermana del rey Federico Guillermo II de Prusia. Está situación provocó una inevitable escalada de hostilidades a nivel diplomático, amenazando directamente con una guerra entre ambas potencias. Este conflicto se originó con la convención angloprusiana de octubre de 1787, la que evolucionó posteriormente con los tratados de alianza anglo-holandés y pruso-holandés del 15 de abril de 1788, y con el tratado de la alianza defensiva anglo-prusiano de 1788². Restaurado el gobierno del Estatúder, y perdida la influencia borbónica en los Países Bajos, Francia amenazó con la declaración de guerra.

Es en este contexto que la corona española, a través de Carlos III, tuvo una participación determinante en dicha disputa diplomática al adoptar una posición de mediador y conciliador entre ambas partes. Como solución, se estipuló la reinstauración del gobierno legítimo del Estatúder, mediante un tratado firmado el 17 de octubre de 1787. Sus cláusulas apuntaron a limitar y regular el armamento naval de sus escuadras. Carlos III, sin embargo, como parte de su política de seguridad imperial, dio un apoyo incondicional a la corona francesa, comprometiéndose con la asistencia militar en caso de que la Gran Bretaña incumpliese el tratado3. Esta política de la corona española respondió a la amenaza en común que representó Inglaterra para sus intereses imperiales dinásticos 4 .

En el ámbito americano, Carlos III adoptó medidas preventivas de protección para sus colonias. Adelantándose a las posibles eventualidades, el ministro Antonio

2 Anderson, M., “European Diplomatic Relations, 1763-1790”, en Goodwin, A., ed., The New Cambridge Modern History. Volume VIII, Cambridge University Press, London, 1976, 275.

3 Lafuente, Modesto, Historia General de España. Tomo decimoquinto, Montaner y Simon Editores, Barcelona, 1889, 15-16.

4 El conflicto diplomático en 1789 entre España y Francia contra Gran Bretaña por los derechos españoles de la bahía de Nootka-Sound fue otro factor que se sumó a esta escalada militar. El desencadenante del problema fue la captura de dos embarcaciones inglesas por fuerzas españolas, que consideraron su presencia, durante el mes de junio, como una violación del espacio marítimo. El trasfondo de este conflicto fue la disputa por el control del Mar del Sur. Véase: Calvo, Antonio, "Génesis del II Imperio Británico y Ocaso del Universalismo Español: La Doble Vertiente del Conflicto de Nootka (1790)", HISPANIA, Revista Española de Historia, LXVIII/228, 2008, 152-153. 
Valdés, quien era secretario de Estado y del Despacho Universal de Marina e Indias, el 6 de octubre de 1787, once días antes de que se firmase el tratado de desarme naval, mandó recomendaciones de precaución a Teodoro de Croix, Virrey del Perú. El Rey de España le solicitó "poner en el mejor estado de defensa las plazas de la comprehensión del Virreinato de su mando, a cuyo fin comunicará sus órdenes reservadas a los respectivos Gobernadores"5. La ejecución de esta Real orden recién se aplicó el día 28 de marzo de 1788, remitiéndose copias a las intendencias de Trujillo, Arequipa y Chiloé, como también al Inspector General y al presidente de Chile. El Virrey comentó a los gobernadores que las noticias recibidas "son favorables, e indican que las turbaciones de Europa están ajustadas"6. A pesar de esta relativa calma en el ámbito de las relaciones internacionales, aun así sugirió a los Intendentes continuar con las medidas defensivas en los puertos y distritos de sus mandos, debiendo implementar sus gobernadores anticipadamente planes preventivos de defensa militar en las zonas costeras. Lo anterior debía ser ejecutado sin comprometer el erario de la Real Hacienda, ni ser expuesto abiertamente a la opinión pública.

Esta especial preocupación de reducir al máximo el gasto fiscal tuvo su origen en las políticas de austeridad imperial que Carlos III implementó a través de su Real decreto del 29 de junio de 1785, a causa de las múltiples deudas contraídas durante la Guerra de la Revolución Americana7. Los préstamos y suministros de armas y municiones entregadas en apoyo de Francia y de los revolucionarios americanos, como el gasto general que implicó movilizar a sus propias fuerzas coloniales, causó un fuerte endeudamiento en la Real Hacienda ${ }^{8}$. Sin embargo, la trascendencia de esta política fue su aplicación conjunta entre España y sus posesiones americanas, por lo que fue un preludio de la posterior unificación de las finanzas de España con las de

\footnotetext{
Archivo Nacional Histórico de Chile (ANH), Fondo Archivo Administrativo de Arica (AAA), leg. 6, pieza 8, f. 1r. ANH, AAA, leg. 6, pieza 8, 2r.

España participó en este conflicto de forma independiente y en alianza con el imperio francés, entre los años 1779 y 1783. A pesar del fracaso español en la recuperación de Gibraltar e isla de Jamaica, las sucesivas victorias militares en el Golfo de México, principalmente con el decisivo asedio de Pensacola en mayo de 1781, como la recuperación de la isla de Menorca en el mediterráneo, representaron la efectividad alcanzada en las reformas militares imperiales después del desastre de La Habana. Por medio del tratado de paz con Gran Bretaña, España obtuvo las provincias de Florida Oriental y Occidental, como también el pleno control territorial del litoral del Golfo de México. Véase: Andrien, Kenneth y Kuethe, Allan, The Spanish Atlantic World in the Eightheen Century. War and The Bourbon Reforms, 1713-1796, Cambridge University Press, New York, 2014, 305-306.

8 Según Allan Kuethe, a comienzos de la década de 1790, el gasto por concepto de mantenimiento de la Armada Española, que en aquel entonces era la segunda potencia naval detrás de Inglaterra y que respecto a ésta alcanzaba a ser los dos tercios de su total, era igual al de las rentas reales procedentes de América. En palabras de Kuethe, "la Armada devoraba los frutos del colonialismo por sí sola". Véase: Kuethe, Allan. "La crisis naval en tiempos de Carlos IV", Boletín de la Real Academia Sevillana de Buenos Letras: Minervae Baeticae, 42, 2014. Sevilla, 269-273.
} 
Indias9. El ministro Lerena, responsable de los ministerios de finanzas y de guerra, se encargó de buscar el modo de mantener un presupuesto militar acorde a la nueva realidad financiera del gobierno. Sería en 1786 cuando se recurrió a una pequeña pero revolucionaria modificación de la organización militar de América. Consistió en sustituir el régimen de la rotación de los regimientos por el aumento de los soldados, a través de la conscripción en las propias colonias para los batallones fijos de los principales fuertes del imperio. No obstante, esta política económica obligó a contradecir el principio político de no aumentar el poder de los criollos dentro del ejército colonial ${ }^{10}$.

En el caso del Virreinato del Perú, y más concretamente en la Intendencia de Arequipa, área administrativa en que se circunscribió el partido de Arica, el virrey de Croix previno al intendente Antonio Álvarez y Jiménez ${ }^{11}$, en marzo de 1788, la noticia del tratado de desarme mutuo de las armadas de Francia y Gran Bretaña, lo que aseguraba una tranquilidad momentánea del tránsito comercial entre las colonias con la metrópoli. Sin embargo, instó a que se mantuviesen los preparativos defensivos ${ }^{12}$. De este modo, dicha orden central estipulada por de Croix fue el punto inicial que dio origen a un plan de defensa general para proteger las costas de la Intendencia de Arequipa, y que, dada las circunstancias particulares del puerto de

9 El ministro Pedro López de Lerena le extendió, en el mismo año, la Real orden de Carlos III a José de Gálvez, visitador de Nueva España. Véase: Andrien, Kenneth y Kuethe, Allan, The Spanish Atlantic World in the Eightheen Century, 317. En 1787, con la creación de la Junta Suprema de Estado por decreto del 8 de julio, Carlos III no solo buscó establecer la relación interministerial de su gabinete de gobierno, sino que además se enfocó en transformar la administración americana en dos grandes grupos: por un lado, el de 'Guerra, Finanzas y Comercio', y el otro en el de 'Gracia y Justicia'. Esta política representó una continuación de las tendientes reformas borbónicas a una mayor centralización y control del gobierno imperial. Véase: Kuethe, Allan. "La crisis naval en tiempos de Carlos IV", 319.

10 Kuethe, Allan. "La crisis naval en tiempos de Carlos IV", 318.

11 Antonio Álvarez y Jiménez tenía el cargo de Gobernador Intendente y Vice Patrón Real de la Provincia de Arequipa, como también el rango militar de Teniente Coronel de Ejército. Archivo General de Simancas (AGS), Secretaria de Estado y del Despacho de Guerra (SGU), leg. 7132, 5, parte 1, f. 5r-12r. En términos generales, la amplia experiencia política y militar que poseyó este intendente no solo se debió a su gran formación intelectual, sino que también a los diversos gobiernos políticos a los cuales fue destinado por el rey de España. Una muy buena reseña biográfica al respecto es la presentada por el historiador Carlos Choque Mariño, el cual expresó lo siguiente: "El segundo intendente de Arequipa nació en Vigo, Pontevedra, provincia de Galicia. (...) Ingresó al ejército real a temprana edad, adquiriendo una amplia experiencia en sus años de servicio, pues ejerció sus funciones en Lima, Buenos, Melilla y Andalucía, llegando a participar en el sitio de Gibraltar. Alcanzando al final de su carrera militar el grado de brigadier general de los ejércitos de Su Majestad. Asimismo, obtuvo una formación ilustrada, que luego le será útil en su ejercicio de intendente en Arequipa. Después de ascenderé a brigadier, fue relevado del gobierno de Arequipa y pasó a la provincia de Chiloé como gobernador real, quedando en este puesto hasta 1812 (...)". Véase: Choque, Carlos, Anttonio Álvarez y Ximénez. La visita al partido de Arica, 1793, Ediciones Universidad de Tarapacá, 2018, 37.

12 ANH, AAA, leg. 6, pieza 8, f. 2v. Esta política de austeridad económica obedeció a las reformas del gasto fiscal del Virreinato del Perú, implementadas por el visitador general José Antonio de Areche a partir de 1777. En el ámbito militar, el rubro más afectado fue el mantenimiento de las soldadescas, sector que más coste monetario representaba en el presupuesto de la Real Hacienda. Además, se buscó interrumpir el creciente monopolio que los criollos estaban ejerciendo en los cargos de oficiales de milicia. Véase: Campbell, Leon, "After the Fall: The Reformation of the Army of Peru, 1784-1816", Ibero-amerikanisches Archiv, 4/1, 1977, 7. 
Arica, declarado en 1778 por Carlos III como único puerto de libre comercio del sur peruano, fue motivo suficiente para que se estableciese su Comandancia General en dicha ciudad. El partido de Arica concentró a las principales autoridades militares que dirigieron la planificación y ejecución de la defensa, lugar desde el cual distribuyeron el envío de refuerzos y suministros a las demás localidades costeras de la intendencia de Arequipa.

A manera de hipótesis preliminar, un elemento crucial de este plan de defensa fue que sus lineamientos estratégicos se ajustaron a los principios de la guerra defensiva propuestos por el Marqués de Santa Cruz de Marcenado, ilustre pensador militar español de la primera mitad del siglo XVIII que influyó en la concepción europea del arte de la guerra de todo aquel siglo. Según Marcenado, lo fundamental de la guerra defensiva no es lograr la neutralización de la ofensiva enemiga, sino preparar todas las medidas necesarias para que, en caso de que se sufra la derrota en el combate, se pueda reorganizar nuevamente el ejército sin que se dispersen sus fuerzas. No obstante, en lo que atañe a las relaciones cívico-militares, este plan estratégico provocó una polarización entre las autoridades políticas con la dirección militar, como también entre los oficiales de milicias americanos con los oficiales veteranos de origen español. Esto último es considerado, a manera de hipótesis central, como el principal factor que impidió el buen funcionamiento y preparación del sistema defensivo de la Intendencia de Arequipa.

\section{El sistema estratégico defensivo del partido de Arica}

En Arica, el plan de defensa constó de la implementación de un sistema de vigilancia costero en los puntos estratégicos que requerían de una mayor protección, para lo cual se seleccionó el mismo puerto de Arica, y a las restantes caletas de Vitor y de Camarones, ubicadas hacia el sur. Desde el punto de vista geográfico, el partido de Arica posee una extensa cadena montañosa costera que servía de defensa natural, a excepción de las áreas donde se situaban los tres puertos, debido a que son zonas de desembocadura de cursos fluviales, y por tanto únicas vías de acceso hacia el interior del territorio ${ }^{13}$. Como complemento a este sistema de vigilancia, el

13 A cada uno de estos centros de vigilancia se ordenó que se compusiera de "dos hombres, Españoles, Negros, o Mulatos agiles, y expertos". Véase: ANH, AAA, leg. 7, pieza 80, f. 1r. El oficial de milicias encargado de las zonas de Vitor y Camarones fue Francisco Xavier Henrriquez, comandante de la compañía de milicias de Codpa. ANH, AAA, leg. 7, pieza 95, f. 1r. La referencia indistinta de milicias de diversos orígenes étnicos en la vigilancia es una evidencia de la aplicación de la estructura militar del reglamento de milicias de Cuba en el partido de Arica. 
Virrey del Perú dispuso de un navío de guerra llamado San Pablo para los fines de exploraciones de las costas del Mar del Sur ${ }^{14}$. Entre las justificaciones que posiblemente forzaron esta decisión estratégica, se cuenta la noticia del avistamiento de una flota de guerra, de origen desconocido, frente a las costas de la Capitanía General de Chile.

Sin embargo, el único incidente registrado en las cercanías de las costas del partido de Arica fue el abordaje que sufrió el buque guanero La Taratana por un navío ballenero británico, que a lo lejos era acompañado por otras dos embarcaciones. El incidente ocurrió en el sector de Punta de Poli, en las cercanías del puerto de llo, en el partido de Moquegua ${ }^{15}$. Según lo informado por la tripulación, el piloto entregó la carta de navegación con la ubicación de los Puertos de Arica y de lquique ${ }^{16}$. En ese mismo periodo también ocurrieron ataques marítimos que asolaron las costas de los partidos de Tarapacá y de Atacama. El Intendente de Arequipa, enterado de estas noticias, alertó al subdelegado del partido de Arica sobre la gran probabilidad de que amenazasen su puerto, instando que ejecutase en "el mejor modo de defender, combatir, y rechazar cualquier repentinos asaltos; sin dejar de noticiarme por menor cuanto ocurra para mi gobierno"17.

Estas noticias fueron suministradas por el subdelegado del partido de Tarapacá, a causa de que en las costas de su jurisdicción se avistaron embarcaciones "que se juzgan ser enemigas, así por el velamen, y expiaciones de ellas"18. La realidad del avistamiento se evidenció con lo acontecido previamente el 15 de agosto de 1789, donde un buque de mediano porte intentó desembarcar en las caletas de Tocopilla y de Duendes, en el partido de Atacama. De acuerdo al testimonio de un grupo de indios de esa zona, obtenido por el oficial de milicias Antonio Contreras, fue en la caleta de Duendes que se produjo un asalto y saqueo efectivo "de una casita, en que su dueño depositó varias especies de trigo, ropa de la tierra, pescado, etcétera"19. Este hecho se relacionó con el sonido de varios cañonazos percibidos por los vigías de la zona 20 .

14 El buque de vigilancia procedente del Callao, al mando de Antonio Casuelo, recaló por primera vez en Arica el 21 de agosto de 1789, "a las 7 de la noche". Véase: ANH, AAA, leg. 7, pieza 23, f. 1r.

15 ANH, AAA, leg. 7, pieza 27, fs. 1r-1v.

16 ANH, AAA, leg. 7, pieza 32, f. 1 r.

17 Oficio de 18 de septiembre de 1789. Véase: ANH, AAA, leg. 7, pieza 132: 2r.

1824 de agosto de 1789. Véase: ANH, AAA, leg. 7, pieza 132, f. 1r.

19 Ibid.

20 Ibid. 


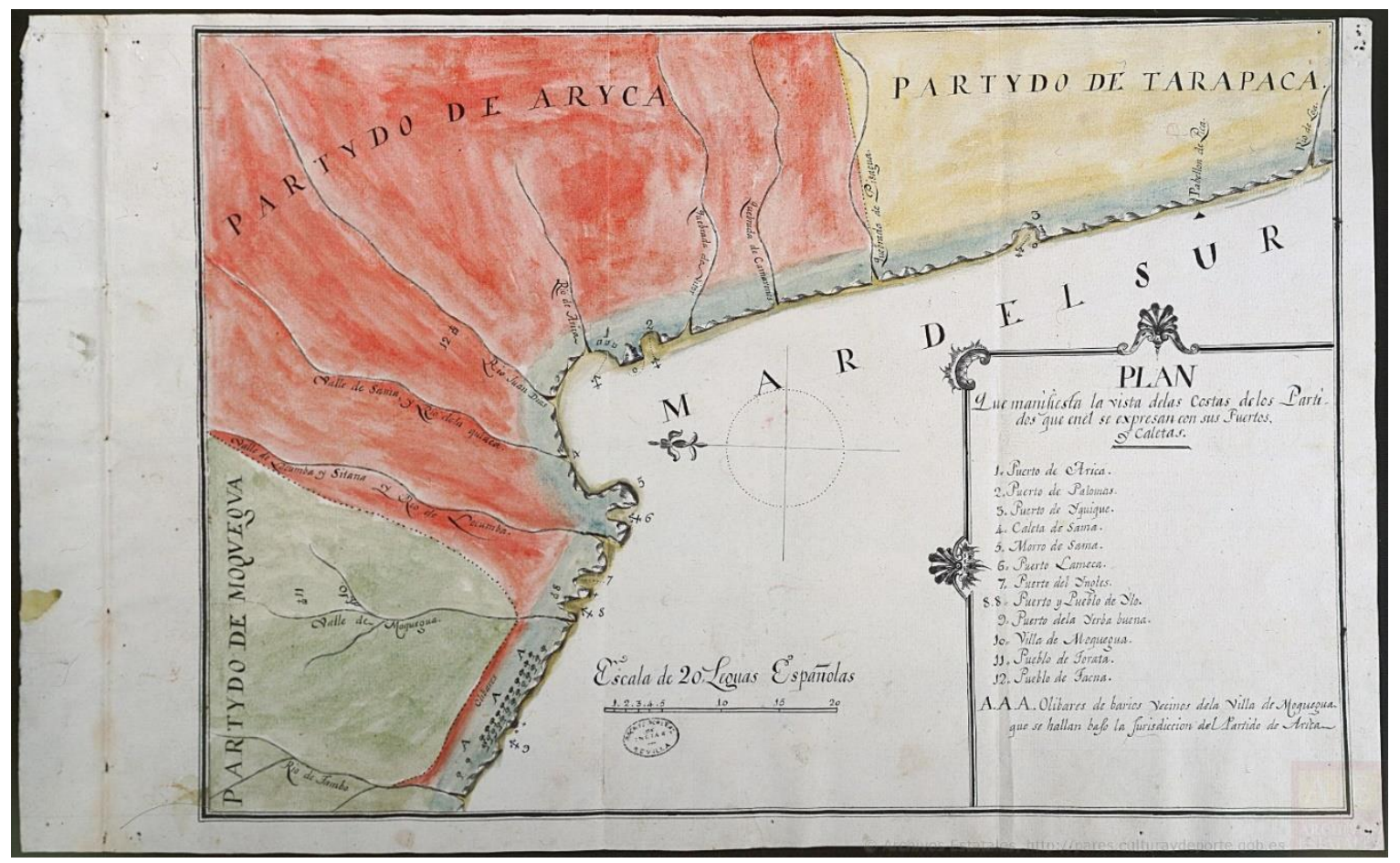

Fig. 1. Mapa de la zona costera del partido de Arica, elaborado en 1791. Fuente: Archivo General de Indias, MPPERU_CHILE, 122. Disponible en: http://pares.mcu.es/ParesBusquedas20/catalogo/description/22730?nm

El intendente Antonio Álvarez y Jiménez especuló que los asaltantes ingleses, que desperdiciaron todas las harinas por no haber podido llevarse consigo la totalidad de los bienes capturado, tenían el objetivo bélico de debilitar la defensa costera a través del desabastecimiento de los suministros de los asentamientos portuarios. En general, consideró esta acción como una advertencia de que los buques británicos "puedan emprender alguna sorpresa en los puertos de la costa de esta Provincia"21, por lo que ordenó al gobierno del partido de Arica "retirar los víveres, y caudales"22 almacenados en el puerto, para que de este modo los enemigos no pudiesen ser socorridos.

También le comunicó al subdelegado de Arica que Juan José de la Lloza, capitán de caballería de milicias, acompañado de 4 soldados de su regimiento, sería enviado con el objeto de verificar e inspeccionar el estado de los puertos y caletas del partido. Le instó a que se le prestasen "todos los auxilios que el comisionado

21 Ibid.

22 ANH, AAA, leg. 7, pieza 132, f. 1v. 
necesite según las noticias que le deberá pasar"23, pues el capitán determinaría las disposiciones cruciales para la defensa. Sin embargo, el estado defensivo de Arica no cumplía con el mínimo requerido. Así se lo hizo saber el comandante Josef Lino Portocarrero al subdelegado, comunicándole que "se carece totalmente de los fragmentos de guerra, y proporciones útiles para arbitrar cualquier ocurrencia" 24 . Mismo problema sucedía con el contingente de las milicias, pues en aquel periodo el partido se componía de 3 compañías, las que correspondían respectivamente a la ciudad de Arica, sus valles circundantes de Lluta y Azapa, y por último al cacicazgo de Codpa ${ }^{25}$. Sólo la compañía de Arica y de Azapa, que era la primera línea de defensa, apenas reunía "cuarenta y tantos hombres"26.

La principal medida de seguridad adoptada en el puerto de Arica fue la implementación de un sistema de revisión aduanera del cabotaje. La responsabilidad estuvo a cargo de los matriculados de marina. Sin embargo, por falta de personal, el subdelegado Tomás de Menocal ideó mitigar el problema con el apoyo de las milicias urbanas, hecho que le fue denegado por el comandante de esa compañía. El oficial responsable argumentó que, por la inexperiencia de la milicia en el rubro portuario, "no parece regular que solo este tan corto número de milicianos, hayan de resistir el peso que carga una diligencia de esta naturaleza"27. Preocupado por el estado general de movilización real de las milicias del partido de Arica, el intendente Álvarez solicitó al subdelegado el envío de "los pies de listas de tropas milicianas de ese territorio, con las noticias particulares, que ocurran en la costa"28, con el objeto de "poder formar concepto cabal de su estado"29. Dentro de los planes de defensa estaba el objetivo esencial de mejorar la calidad de las milicias mediante la instrucción y adiestramiento ${ }^{30}$. Para lograr este fin, y consciente de la falta de unidades experimentadas, forzó al virrey de Croix a que mandase "un piquete de

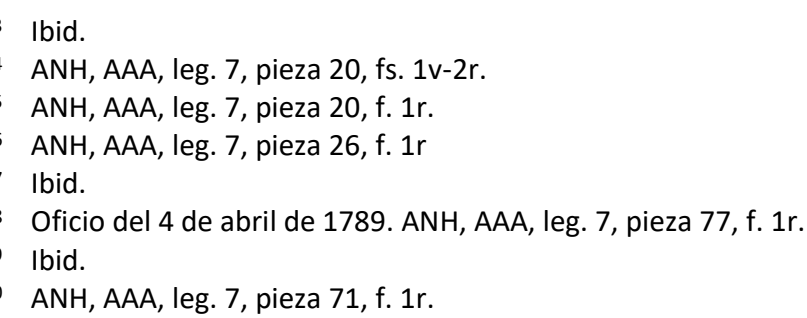


soldados veteranos ${ }^{31}$ del regimiento Real de Lima"32, compuesto de un teniente, un sargento, dos cabos, un tambor, y dieciséis soldados.

El intendente también solicitó que a la sección de infantería se le cobrasen los víveres que necesitasen de acuerdo al precio vigente en el mercado, y que el pago del sueldo estuviese a cargo de los ministros foráneos de Tacna. Además, en el cabildo quedó la responsabilidad de entregar el alojamiento. Sin embargo, lo más importante de la llegada de este refuerzo era el suministro de armas y municiones. En ese sentido, dicho piquete traía consigo "200 fusiles con sus respectivas fornituras, diez mil cartuchos con bala, y ochocientas piedras de chispa"33, la que quedaría bajo la custodia del subdelegado de Arica, y sólo sería entregado a las compañías de milicias en caso de una emergencia para la defensa del puerto. En el ámbito político-militar, dio cuenta que las unidades veteranas quedarían al mando del subdelegado. Por último, dio una serie de disposiciones y consejos en el ámbito estratégico y táctico para que se ejecutasen de acuerdo al plan de defensa. En lo estratégico, Antonio Álvarez ordenó movilizar todo el recurso humano disponible para la defensa, pues el objetivo era "no dejar que ponga pie en tierra el enemigo de la corona, que como tales se deben reputar los ingleses en las circunstancias presentes; negándoles todo auxilio de víveres, aguadas, etcétera"34, debiendo el mismo subdelegado de Arica informar de estas medidas a "sus subalternos de las costas". En lo táctico, ordenó que los dos cañones de 6 libras, situados en Arica, se posicionasen en un lugar donde se aprovechase al máximo su potencial de fuego. Para ello mandó a que, en conjunto con el oficial veterano, explorase el terreno más ventajoso para situarlo. El objetivo radicó en que de dicha posición "sus fuegos, y direcciones dominen la playa del desembarco, y puedan impedirlo". Además, aconsejó para la defensa de las tropas la construcción de parapetos, que, en conjunto con los saquillos de metralla y los dos barriles de pólvora, que el mismo piquete de soldados acarreaba, se empleasen en conjunto para "hacer una vigorosa defensa" 35.

31 De acuerdo a Juan Marchena, las unidades militares veteranas compusieron al denominado 'Ejército de Dotación', las que se guarnecían en las principales ciudades de las provincias americanas. Estas eran de carácter defensivo, organizadas de acuerdo a la estructura existente en España, pero con la diferencia que sus tropas eran de procedencia americana. Su importancia radicaba en que conformaron el "núcleo fundamental del Ejército de América". Véase: Marchena, Juan, "El ejército de América y la descomposición del orden colonial. La otra mirada en un conflicto de lealtades", Revista Militaria, 4, 1992, 72.

32 ANH, AAA, leg. 7, pieza 24, f. 1 r.

33 ANH, AAA, leg. 7, pieza 24, f. $1 \mathrm{v}$.

34 Ibid.

35 ANH, AAA, leg. 7, pieza 24, f. 2r. Sobre los saquillos de metrallas, puntualizó que se utilizasen por su bajo costo de producción, empleando como materiales pedazos de plomo o cualquier otro metal a disposición. 
Lo interesante de la planificación de defensa del intendente Álvarez y Jiménez es que fue una demostración de su formación intelectual como oficial militar. En este documento expuso su concepción de lo que es el arte militar, el cual definió como "proporcionar la retirada y más ventajosa en el caso forzoso de ejecutarse"36. Este principio táctico se refiere a que la selección y preparación del teatro de operaciones, como también del mismo campo de batalla, siempre debe apuntar en facilitar el repliegue y retirada del ejército para un posterior rearme de las fuerzas. Fue el Marqués de Santa Cruz de Marcenado el que desarrolló este principio en su voluminosa obra titulada Reflexiones Militares, publicada en la década de 1720. Marcenado fue uno de los principales intelectuales militares del siglo XVIII, pues sus reflexiones influyeron en el pensamiento estratégico de importantes generales, tales como Federico II de Prusia y Napoleón Bonaparte 37. De acuerdo a Marcenado, el punto esencial a considerar en el contexto de una guerra defensiva es que "La mayor dificultad, en volver a completar un exercito derrotado, suele hallarse de parte de quién sostiene la Defensiva"38. Sobre la razón de esta afirmación concluyente, Marcenado lo dejó bastante claro: "Con que peleando interin que tu Guerra es Defensiva, irías a ganar solo una batalla, o a perder el combate y la provincia"39.

Mismo principio fue afirmado por el francés Vaultier en su obra titulada Observaciones sobre el arte de hacer la Guerra. Su traducción fue hecha en 1773 por el sargento mayor de infantería Basilio Gascon, y dirigida al conde de O'Reilly para que dispusiera de este tratado para la formación de los jóvenes militares. Vaultier consideró a la acción de retirada como un aspecto táctico militar de mayor trascendencia que el objetivo mismo de ganar un combate, pues afirmó que "Tanto mérito hay, y aun tal vez mayor en saberse retirar a tiempo, y con orden, después de la perdida de una acción desgraciada, como en ganar una Batalla"40. Por tales razones, si se diese la necesidad de la retirada de las milicias de Arica, abandonando el puerto y ciudad al control de los británicos, el Intendente de Arequipa ordenó que los cañones se instalasen de tal manera que "no sean útiles a los enemigos", por lo

36 Ibid.

37 Garate, María, "Las reflexiones militares del Marques de Santa Cruz de Marcenado", Revista de Historia Militar, XXIX/núm. Especial, 1985, 21.

38 Marqués de Santa Cruz de Marcenado, Reflexiones Militares. Tomo X, Juan Francisco Mairesse, Turín, $1727,13$.

39 Marqués de Santa Cruz de Marcenado, Reflexiones Militares..., 14.

40 Vaultier, Observaciones sobre el arte de hacer la Guerra, Imprenta de Pedro Marín, Madrid, $1773,84$. 
que puntualizó que estos estuviesen clavados con arpones para dejarlos totalmente inmovilizados ${ }^{41}$.

La extrema cautela adoptada en los preparativos defensivos, no correspondieron a unas medidas autónomas de la gobernación de Arequipa, sino que obedeció a la continuación de la política estratégica del Virreinato del Perú iniciada en los años 1766-1768, periodo en el que fueron capturadas las islas Malvinas por los británicos, acción que tuvo el objetivo geopolítico de proyectar su influencia imperial en el atlántico sur. Aquello fue sintetizado en un reporte titulado "Estado del Perú", elaborado el 25 de febrero de 1769 por el Marqués de Grimaldi, ministro de Asuntos Exteriores de Carlos III, con el fin de que se adoptase en el Ministerio de Indias. El documento fue un estudio sobre las reformas militares que el Perú necesitaba adoptar para su defensa, ante el interés británico de obtener control sobre parte del territorio continental americano, ya que, a excepción de la guarnición de la plaza fuerte del Callao, el resto de la costa del Perú estaba indefensa, por lo que el refuerzo de soldados y municiones para su protección era el objetivo principal que se debía cumplir42.

En ese contexto, una de las primeras medidas adoptadas por el subdelegado del partido de Arica fue la reparación "de los dos cañones de a seis que existen en el puerto de Arica"43. Antonio Álvarez y Jiménez le instó a Menocal que recurriese a todas las armas posibles que poseyese el vecindario de la ciudad de Arica en caso de urgencia, como también que informase constantemente a su gobierno sobre el desarrollo de los acontecimientos en el partido44. El plan de defensa fue una medida adoptada en razón de la importancia del puerto y ciudad de Arica. En aquel periodo dicho puerto era un centro nodal de libre comercio, designado por Carlos III en 177845. Históricamente, el puerto de Arica fue el centro de articulación económico del Mar del Sur para las provincias de la Audiencia de Charcas ${ }^{46}$. Esto originó una extensa red

41 ANH, AAA, leg. 7, pieza 24, fs. 2r-2v.

42 Campbell, Leon, "The military reform in the viceroyalty of Peru, 1762-1800". A dissertation presented to the graduate council of the University of Florida, in partial fulfillment of the requirement for the degree of doctor of philosophy, University of Florida, 1970, 63.

43 ANH, AAA, leg. 6, pieza 15, f. 2r.

44 ANH, AAA, leg. 6 , pieza 15 , fs. $2 r-2 v$.

45 Reglamento y aranceles reales para el comercio libre de España a Indias de 12 de octubre de 1778, Imprenta de Pedro Marín, Madrid, 1778, 9.

46 Pedro de Ureta, tesorero de la Caja Real del Corregimiento de Arica, dio constancia, a fines de la década de 1770, que el puerto de Arica estaba catalogado entre los principales del Mar del Sur, lo que hacía de esta cuna puerta benéfica de enlace social que franqueaba la introducción de mercaderías y frutos procedentes de Chile, Guayaquil y Panamá con destino a las provincias interiores de La Paz, Oruro, Charcas y Potosí. Entre los productos que se 
comercial en torno a la arriería, dada la diversidad de insumos y mercancías que demandaban los grandes centros productivos y comerciales de las provincias de Charcas, lo que posicionó a Arica en abierta competición con los comerciantes del Cuzco y Arequipa ${ }^{47}$. Sin embargo, esta red comercial minera desapareció cuando la ruta de exportación-importación fue trasladada en dirección al puerto de Buenos Aires ${ }^{48}$. Sin embargo, durante los periodos de bloqueos marítimos experimentados por el Virreinato del Río de la Plata, a causa de los conflictos internacionales con Gran Bretaña, el circuito comercial Tacna-Arica lo sustituiría temporalmente como centro principal de abastecimiento para los navíos provenientes de la ruta marítima atlántica ${ }^{49}$. Es así que su posible captura por fuerzas británicas implicaba no sólo el aislamiento comercial del sur del virreinato del Perú, sino también el bloqueo comercial y comunicacional con las provincias de La Paz y Potosí. No es de extrañar la importancia que el Intendente de Arequipa le atribuyó al puerto de Arica en la siguiente carta enviada a Menocal:

"Siempre ha sido uno de los más principales cuidados que me rodean sobre esta materia el resguardo, y custodia del puerto de Arica como que en el se ha experimentado en tiempos pasados por la misma nación Británica desembarco, y hostilidad en su ciudad, y así por los justos recelos de ser franco, y reconocido su fondeadero es indispensable el que vuestra merced pase a ella con el fin de estar más próximo para librar las Providencias, y ordenes que convengan a su mejor seguridad, y a que en el caso desembarco no consiga el enemigo los fines de su empresa" 50 .

A lo anterior se sumó la orden para que, en conjunto con el teniente del piquete, revisasen el cañón de 12 libras que se situaba en las playas del puerto de

comerciaban, se encontraban el ají, aceite, algodón, vino y aguardientes, pescado seco, etc. Véase: Dagnino, Vicente, El corregimiento de Arica, Imprenta La Época, Arica, 312.

47 Choque, Carlos y Muñoz, Iván, "El Camino Real de la Plata. Circulación de mercancías e interacciones culturales en los valles y Altos de Arica (Siglos XVI al XVIII)", Revista Historia, Santiago, 49/I, 2016, 58.

48 La creación del Virreinato del Río de la Plata en 1776 obedeció a una reforma administrativa de carácter estratégicomilitar. Los fracasos de las expediciones militares organizadas por el gobierno virreinal del Perú, durante la disputa de la colonia de Sacramento contra la corona portuguesa, forzó al gobierno de Carlos III a centralizar el mando y los recursos de la defensa en Buenos Aires. Consecuentemente, por los problemas administrativos del gobierno de Lima en la Audiencia de Charcas y por la importancia económica de la producción minera de plata para el sostenimiento de la defensa de la costa atlántica americana, se optó por ser anexada al nuevo virreinato. Véase: Campbell, Leon, The military reform in the viceroyalty of Peru, 97.

49 Rosenblitt, Jaime, Centralidad geográfica, marginalidad política: La región de Tacna-Arica y su comercio, 1778-1841, Dibam, Santiago, 2013, 93.

50 ANH, AAA, leg. 7, pieza 32, f. 2 r. 
Arica, con el objeto de "si es posible habilitarlo, y hacerlo servible"51. Para que todas las anteriores disposiciones y mandatos pudiesen cumplirse de la mejor forma, como también el de informar lo más rápidamente los sucesos que acontecieran en el puerto, le dio el último consejo de residir en la ciudad de Arica, capital del Partido. Una de las características especiales del partido de Arica fue que las autoridades administrativas tuvieron su residencia en Tacna, a pesar de ser nominalmente la ciudad de Arica la capital del partido. Esta decisión se dio en el contexto de la sublevación de Túpac Amaru II, ya que, a manera de resguardo, las autoridades civiles se refugiaron por la amenaza que las comunidades indígenas rebeldes hicieron a la ciudad de Arica. También fue un factor determinante su permanente exposición a los ataques costeros británicos. Instaurado el sistema de Intendencias en 1784, se confirmó dicha designación de la residencia de las autoridades políticas en Tacna52.

En vista de los diversos aprestos militares que eran necesarios emplear, el intendente de Arequipa deliberó aumentar el envío de la cantidad de armas y municiones, las que serían trasladadas por el piquete de soldados veteranos del regimiento Real de Lima. De esta manera, Antonio Álvarez y Jiménez aumentó el envío adicional en 100 fusiles, 5.000 cartuchos con bala y 400 piedras, lo que lo dejó en un total de 300 fusiles, 15.000 cartuchos y 1.200 piedras de chispas ${ }^{53}$. Esta decisión se dictaminó por el envío de un oficio de reclamación dirigido al Virrey, hecho por el oficial Fernando de Soto y demás capitanes de milicias del Partido de Arica. La causa de la queja fue que en el puerto de Arica "no hay resguardo alguno, para en caso de cualquier invasión repentina hacer una regular defensa"54.

La denuncia elevada directamente al Virrey causó un gran disgusto en el intendente Álvarez y Jiménez. Este le comentó a Menocal que los oficiales no podían remitirse a la autoridad máxima del Virreinato, pues no debían "entrometerse en adelante a dirigir directamente a aquella superioridad representaciones que no son propias de su incumbencia", sino que estos siempre debían informar toda situación a la intendencia de Arequipa. Era el gobierno provincial quien se encargaba de "la conservación; y defensa de toda la Provincia"55. En virtud de aquello, le encargó dejar

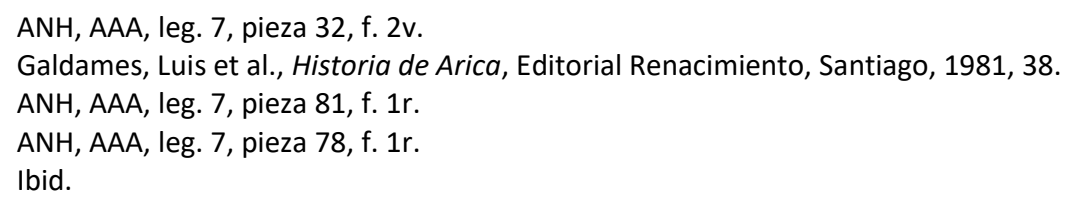


en claro a los oficiales sobre la estructura institucional del mando político y militar del partido de Arica.

\section{Fricción en el mando: conflictos civil-militares}

La llegada del piquete de soldados veteranos del regimiento Real de Lima fue informada el 10 de julio de 1789 al Intendente por el subdelegado de Arica ${ }^{56}$. Para ese entonces se había finalizado la reparación de los dos cañones de 6 libras, como también el seguimiento de la construcción de los parapetos en la costa del partido57. Sólo persistieron las complicaciones en el uso del cañón de 12 libras ${ }^{58}$. A pesar de la necesaria presencia del piquete de soldados veteranos de Lima, en el ámbito de la dirección del mando político-militar de la subdelegación, afectó en la escalada de los conflictos de intereses entre la administración civil y militar. Esta situación fue prevista por el Intendente de Arequipa, que, intuyendo las naturales diferencias que surgirían entre el teniente del piquete y el subdelegado por la subordinación del primero al segundo, le ordenó a Menocal que debía "proceder de acuerdo con el oficial en todo aquello que respecte a intervención del piquete en la ofensiva, defensiva y retirada que instruye el plan respectivo" 59 . Sin embargo, dicha nueva orden mantuvo inalterables las facultades militares del subdelegado de Arica, lo que evidentemente provocó un inevitable quiebre en el mando militar de la defensa. El mismo Intendente, previendo esta posibilidad, le advirtió "que no haya entre ambos la menor altercación hasta que se les dirija la declaratoria"60.

Esta declaratoria era el documento que informaba de la delimitación del mando que tendrían tanto el teniente del piquete de soldados veteranos, como el subdelegado de Arica. De este modo, una de las consecuencias directas que afectaron a Menocal, en relación a la autonomía dada a ambas autoridades, fue el haber perdido el mando militar de las unidades del regimiento Real de Lima, pues, por negativa del mismo teniente, no se le permitió disponerlos para la enseñanza y disciplina militar de las compañías de milicias del partido. Lo anterior era considerado necesario en vista de que los comandantes y oficiales de milicias no tenían los

\footnotetext{
56 La fecha se infirió a partir del oficio del 22 de julio, donde el Intendente le agradeció por el buen trato y acogida que se les dio a los soldados veteranos en Arica.

57 ANH, AAA, Leg. 7, pieza 130, f. 1 r.

58 Ibid.

59 ANH, AAA, leg. 7, pieza 84, f. 1r.

60 ANH, AAA, leg. 7, pieza 83, f. 1 r.
} 
conocimientos mínimos de instrucción para adiestrar a los milicianos. Es así que Antonio Álvarez y Jiménez mandó a Menocal que informase al comandante de la partida de veteranos sobre la solicitud de la prestación de dos soldados de su mando como instructores para la enseñanza y disciplina de las evoluciones militares y manejo de armas a los milicianos del pueblo de Tacna, y a los de la ciudad de Arica ${ }^{61}$.

No obstante, y cambiando totalmente de parecer, fue el Intendente quien reiteró la imposibilidad de emplear a los soldados veteranos para los fines solicitados, pues "en el destacamento que se halla en el Puerto de ese Partido no hay individuo, que pueda disciplinar las Milicias de él, sino es el oficial comandante, o su sargento; $y$ éstos mucho menos pueden separarse de las obligaciones de su cuerpo"62. Este cambio abrupto puso a Menocal en la paradoja de recurrir, como único recurso, a sus oficiales de milicias del partido. La ausencia de oficiales milicianos experimentados en el adoctrinamiento militar, ya fue considerada en 1784 por Manuel de Pineda, inspector general de ejército del Perú, que, mediante los reportes de los subinspectores enviados a constatar las condiciones de las milicias provinciales al término de la sublevación de Tupac Amaru II, concluyó que no sólo estaban mal reforzadas, con la excepción de Cañete y Chancay que tenían sus regimientos en pleno funcionamiento, sino que también poseían un muy reducido número de oficiales de entrenamiento. Para el caso de la Intendencia de Arequipa, representada por las ciudades de Arequipa, Moquegua y Arica, sólo había disponibles seis oficiales de entrenamientos para toda la provincia, conformados de un sargento mayor, un ayudante y cuatro tenientes para un total de tres batallones de infantería de milicias y trece escuadrones de caballería y dragones ${ }^{63}$.

El cambio repentino demostrado por el gobernador de la provincia de Arequipa se explica por el categórico oficio emitido por Gabriel de Avilés, inspector general del Perú64, que por aquella misma fecha le dirigió al Virrey de Croix un informe sobre una disputa similar del mando militar que se dio entre Manuel de Artieda, subdelegado del partido de Moquegua, y el Comandante Veterano de Arequipa. El motivo fue la tropa veterana posicionada en la costa de llo y su relación con las milicias del partido, ante la orden de prevenir la invasión de fuerzas británicas. En aquel documento dio cuenta de las responsabilidades y competencias

61 ANH, AAA, leg. 7, pieza 42, f. 1r.

62 ANH, AAA, leg. 7, pieza 50, f. 1 r.

63 Campbell, Leon, "The military reform in the viceroyalty of Peru", 211.

64 ANH, AAA, leg. 8, pieza 15, fs. 1r-6v. 
administrativas, tanto del cargo de subdelegado como del propio Intendente, que les correspondían de acuerdo a lo establecido en el reglamento de Instrucción de Intendentes. En lo militar sostuvo que los intendentes no podían delegar ningún derecho de autoridad militar a los subdelegados, dado que, primeramente, el Rey jamás les dio a los virreyes tal poder para delegar autoridad militar, y segundo, por el axioma de derecho que dice "que un delegado no puede delegar en otro"65.

En este sentido, Gabriel de Avilés dejó en claro que los soldados en situación de acuartelamiento debían estar, en términos militares, sometidos a las órdenes directas del oficial de su cuerpo, por lo que ninguna autoridad civil podía intervenir en su mando militar. Como ejemplo ilustrativo del caso, dio cuenta de la situación de la provincia española de Murcia, en la que, a pesar de tener una plaza mayor de milicias y un escuadrón de caballería, ningún Intendente ni otro gobernador político se había adjudicado el control del mando militar. Sobre la atribución del mando militar del gobernador precisó que no es otra cosa que la responsabilidad del "manejo de caudales pertenecientes a este ramo"66. En términos simples, en periodos de guerra, la administración política quedaba plenamente subordinada al servicio de los oficiales militares. Sin embargo, el trasfondo de los conflictos civil-militares de la Intendencia de Arequipa fue ocasionado por las continuas disputas jerárquicas de los coroneles de milicias por su situación de subordinación al mando de los oficiales veteranos, los cuales eran de menor rango. Además, el predominio de las milicias locales en el grueso de la defensa incentivó aún más a la elite criolla en el interés de querer dirigir la defensa67.

65 ANH, AAA, leg. 8, pieza 15, f. 2 v.

66 Gabriel de Avilés consideró que da en las autoridades políticas "un mediano talento que uno sublime en la agena", precisando que el dictamen del comandante de la tropa nunca es un voto consultivo del cual quede la decisión final del mando en el subdelegado, ya que las operaciones militares son actos que requieren un análisis inmediato de la situación, dándose de forma simultánea la actividad resolutiva y de ejecución de las decisiones estratégicas. Véase: ANH, AAA, leg. 8, pieza 15, f. 2r. En la real ordenanza de Intendentes se estipuló que, en la causa de guerra, la única responsabilidad del Intendente era la de entregar "su haber en dinero, y su manutención en víveres quando no se haya encargado de ella los mismos Cuerpos". Véase: Real Ordenanza para el establecimiento e instrucción de intendentes de exército y provincia en el Virreinato de Buenos Aires, Imprenta Real, Madrid, 1782, 274.

67 En respuesta a las exigencias de la elite local, Gabriel de Avilés expresó que no se recurriese al uso de las tropas veteranas. Sin embargo, de acuerdo al principio estratégico de no ceder el mando a los oficiales americanos, sostuvo el privilegio de los oficiales veteranos en la dirección de la guerra. La preparación profesional de estos últimos justificaba esta medida. Véase: ANH, AAA, leg. 8, pieza 15, fs. 4v-5r. 


\section{Las reformas militares del virrey Francisco Gil de Taboada}

Después de asumir el cargo de Virrey del Perú el 25 de marzo de 1790, Frey Francisco Gil de Taboada, antiguo oficial de la Armada Española y oficial militar con el grado de Teniente General, ordenó como medida de seguimiento del estado de los regimientos y compañías de milicias del Virreinato, que el Subdelegado del partido de Arica "pase vuestra merced inmediatamente aviso a todos los Coroneles de milicias del Partido de su mando"68 para que efectuasen una revista general de todos las fuerzas milicianas existentes, la que se debía aplicar en día festivo para que se evitase toda interrupción innecesaria en el normal funcionamiento de las actividades de las tropas. Para este censo militar, el Virrey estableció que se considerase únicamente como fuerza efectiva a aquellos que cumpliesen el requisito físico "de agilidad, y robustez competente", y que, a su vez, de dicho grupo se distinguiesen los que poseían cabalgadura. Se solicitó que pusieran "al margen de cada compañía los pueblos de que se compone; expresando solo en número la fuerza de cada una". Además, se especificó el requerimiento del tipo de clima predominante en que se situaban los regimientos, exponiendo si era cálido, templado o frío.

El objetivo de esta revisita general fue la de conservar las listas efectuadas para la buena administración militar del gobierno del partido. El Virrey encargó "que no figuren más gente que la efectiva, ni indulten del alistamiento por contemplación a los que deban ser empleados en este servicio"69, ya que en el caso que se enviase a un inspector militar para observar su cumplimiento, responsabilizarían a los coroneles por la presencia de individuos reclutados que no cumplieran los requisitos de enrolamiento. Por último, ordenó que el subdelegado de Arica le remitiese los informes de las revistas de milicias efectuadas por los coroneles o comandantes de milicias 70 . Estas medidas formaron parte de las reformas imperiales borbónicas, originadas a partir de la desastrosa derrota de España en la 'guerra de los siete años' en 1763, punto de inflexión que redefinió toda la política interior de las colonias, principalmente en lo que respecta a la estructura militar hispanoamericana.

Entre las primeras reformas significativas que marcaron diametralmente el nuevo enfoque imperial destaca la determinación de Carlos III de concentrar en el Marqués de Esquilache los ministerios de finanza y de la guerra. Por la inherente

68 ANH, AAA, leg. 7, pieza 157, f. 1r.

69 ANH, AAA, leg. 8, pieza 15, f. 1r.

70 ANH, AAA, leg. 8 , pieza 15 , fs. $1 \mathrm{r}-1 \mathrm{v}$. 
dependencia de ambos como pilares fundamentales del poder monárquico, su reforma institucional fue considerada como motivo de urgencia para mejorar el sistema defensivo ultramarino ${ }^{71}$. El objetivo de neutralizar posibles invasiones británicas fue el principio estratégico en que continuamente convergieron las nuevas políticas imperiales. La otra reforma estructural, que representó un nuevo paradigma en la organización militar imperial, fue la publicación del "Reglamento para las milicias de infantería, y caballería de la Isla de Cuba" en 1764, doctrina que en los años siguientes sirvió como modelo para el resto de las colonias ${ }^{72}$. Los autores intelectuales de esta materia fueron el Conde de Ricla, nombrado por el Rey como gobernador y capitán general de Cuba, y el mariscal de campo Alejandro O'Reilly, intelectual militar y amigo del primero, al que se le delegó la responsabilidad de la reorganización militar e instauración de las reformas administrativas de la isla73.

En términos generales, la nueva reforma militar apuntó al aumento de los batallones y a la modernización de las milicias de acuerdo a las unidades provinciales de españoles. Cada arma estuvo dividida en infantería, caballería y dragones ${ }^{74}$. Por último, se aplicó la estandarización del adiestramiento y de los uniformes de las diversas unidades. En la estructura jerárquica se abrieron plazas de oficiales para que las conformaran los miembros de las elites locales, lo que aumentaba el vínculo y responsabilidad de los propios habitantes en la defensa de sus intereses. En lo social, se extendió el reclutamiento a los pardos y morenos, formándose compañías de acuerdo a sus orígenes étnicos. La participación de toda la población en masa representó una transformación sociocultural sin precedente en América, pues todas las milicias, sin distinción de sus orígenes, a manera de incentivo tuvieron el derecho de gozar del fuero militar75. Sin embargo, el hecho de que los propios habitantes conformasen el cuerpo principal de defensa, pudiendo incluso estar al mando de

71 Andrien, Kenneth y Kuethe, Allan, The Spanish Atlantic World in the Eighteen Century, 233-234.

72 La primera versión del modelo del sistema de milicias de Cuba que llegó al Perú fue una real orden del 11 de mayo de 1763. Tenía por título "Plan de Milicias: su establecimiento y necesidad". Sin embargo, la primera publicación oficial fue titulada como "Reglamento sobre las milicias del Virreynato del Peru", en 1766. Para el virrey Amat, la reforma militar de las milicias disciplinadas de 1763 no sólo representó una modificación de utilidad, sino que también fue un imperativo requerido por las necesidades estratégicas de aquel momento. Véase: Campbell, Leon, "The military reform in the viceroyalty of Peru", 50-51. El nuevo código militar, en el resto de América, entró en vigencia a partir del año 1765 en las Provincias del Río de la Plata y en Nueva España; en Cartagena de Indias en 1773; en Panamá, en 1773; en 1774 en Guayaquil; Popayán, en 1777; Paraguay, en 1779; Quito y Chile entre 17791780. Véase: Gómez, Carmen, El sistema defensivo americano. Siglo XVIII, Editorial MAPFRE, Madrid, 1992, 58.

73 Campbell, Leon, "The military reform in the viceroyalty of Peru", 240.

74 Es un "Soldado de caballería armado de sable y de fusil con bayoneta, que hacia alternativamente el servicio á caballo y á pié, por cuya razon usaba botines altos en lugar de botas". Véase: D’Waterlet, J., Diccionario Militar, Imprenta de D. Luis Palacios, Madrid, 1863, 274.

75 Campbell, Leon, "The military reform in the viceroyalty of Peru", 240-241. 
oficiales pertenecientes a las elites terratenientes, fue considerado por las autoridades civiles coloniales como un potencial foco de desestabilización. Por tales motivos, se mantuvo el principio de que los regimientos de soldados veteranos, de origen español, controlasen y dirigiesen la organización e instrucción militar, como también el de detentar el control de la tenencia de armas. Del mismo modo, se mantuvo el principio de que los oficiales americanos estuviesen subordinados al mando de los oficiales veteranos.

Enterado de la debilitada institucionalidad de las milicias, afectada principalmente por la falta de preparación e incapacidad de orden y mando, como también de los múltiples conflictos de poder generados entre las autoridades políticas y militares, el virrey Francisco Gil mandó al Intendente de Arequipa, en un oficio del 16 de abril de 1792, que aplicase una serie de reformas enfocadas en la regularización de la orgánica y funcionalidad del sistema del mando y dirección del ejército, reestructurando la jerarquía dentro de la oficialidad militar. Lo anterior correspondió a medidas vinculadas a la Real orden del 22 de agosto de 1791 sobre el arreglo de las milicias del Virreinato, emitida por Carlos IV para reforzar los requerimientos de la defensa militar. También empleó como línea directriz los consejos de Gabriel de Avilés, que, en un reporte de 16 de mayo de 1792, recomendó, aparte de la necesidad de disolver aquellas compañías de milicias limeñas mal entrenadas y comandadas por personas que se atendían a sus intereses privados, el de emplear a los subdelegados como asistentes auxiliares en las compañías. Sin embargo, el punto fundamental que planteó fue el de confiar a los hacendados locales la comandancia de los batallones de milicias, pues solucionaría el problema de las deserciones dentro de las filas al ser estos también sus jornaleros y empleados dependientes ${ }^{76}$. Es en base a esto que se efectuaron las consiguientes regularizaciones dentro de la estructura de los oficiales de milicias, lo que depuró y preparó el mando militar para la defensa del Virreinato.

En el ámbito de la jerarquía militar, el Virrey estipuló que los oficiales de milicias recibiesen "las gracias, y ascensos que según sus méritos y servicios les pertenezcan"77, no siendo esto extensible a aquellos que poseyeran nominalmente el título de oficial de milicias. Para el caso de la organización de las tropas milicianas, el Virrey encargó que "solo haya dos clases de Milicias con la denominación de disciplinadas78 y

76 Campbell, Leon, "The military reform in the viceroyalty of Peru", 235-236.

77 ANH, AAA, Leg. 8, pieza 4, f. 1 r.

78 La milicia disciplinada es aquella "que se rije por reglamentos y ordenanzas, estando bien instruida en el manejo de las armas y movimientos tácticos = Epiteto de ciertos cuerpos de infantería y caballería que en nuestras posesiones 
urbanas79"80. También que se cancelase el grado de oficial a los individuos que "se separen del distrito de su cuerpo, o que de cualquier otro modo no continúen en el ejercicio de sus empleos", implicando que no podrían "usar de su divisa, y uniforme", como tampoco el de solicitar nuevos empleos cuando existiesen vacantes de oficiales en las compañías de los lugares en que establecieran su residencia. Lo único a lo que podrían optar era al derecho de pedir licencias, las que serían emitidas por los respectivos jefes militares de la zona a la que pertenecieran. Para el caso en que esto último no fuera factible, podrían optar al "retiro con el goce de fuero militar, si por sus servicios fuesen acreedores a él"81. Entre los oficiales de milicias afectados por la ordenanza militar fiscalizadora de Carlos IV, sólo se tiene constancia del caso particular de Ignacio Enrique Portales, escribano público de cabildo del partido de Arica. Fue penalizado con la prohibición "de la gracia de llevar uniforme, y titularse oficial militar en lo judicial, o extrajudicial"82, a consecuencia de no haber presentado los documentos originales que certificasen su grado de coronel de milicia, ya que justificó ilegítimamente su empleo de oficial a través de testimonios, lo que incumplía con los requisitos legales exigidos.

El Virrey, continuando con la ejecución de la Real orden, le exigió al intendente Antonio Álvarez y Jiménez que instaurase la medida obligatoria a todos los oficiales hacendados que tenían sus regimientos en la jurisdicción del partido de Arica, para ser considerados como habitantes de dicha zona, aunque estuviese situada su residencia en otra región83. Además, contando desde la fecha de su publicación, le ordenó que diese un límite máximo de 20 días para que todos informasen sobre su situación de alojamiento. Sin embargo, para aquellos oficiales que no despachasen la verificación de su residencia, el Virrey ordenó que a estos se les penalizase con sus títulos militares, quedando estos "nulos de ningún valor ni efecto", como también la negación del derecho de "gozar del fuero y uniforme", de acuerdo al "reglamento de milicias de Cuba" ${ }^{4}$. Luego de recopilada la información de residencia de los

de Ultramar se crearon con naturales del pais para auxiliar en el servicio á los regimientos peninsulares". Véase: D'Wartelet, Diccionario Militar, 508-509.

79 Son aquellas "que se formaban en las ciudades, cuya organización y armamento dependian de las autoridades municipales, pero que en caso de peligro se ponían á las órdenes de los gobernadores". Véase: D'Wartelet, Diccionario Militar, 511.

80 ANH, AAA, leg. 8, pieza 4, f. 1 r.

81 ANH, AAA, leg. 8, pieza 4, fs. 1r-1v.

82 Así sentenció el virrey Frey Francisco Gil en decreto del 30 de agosto de 1793, informándoselo a Tomás de Menocal, en oficio con fecha 2 de septiembre de 1793. ANH, AAA, leg. 8, pieza 142, fs. $1 \mathrm{r}-1 \mathrm{v}$.

83 ANH, AAA, leg. 8, pieza 4, f. 1v.

84 Ibid. 
oficiales, se dictaminó que el intendente debía hacer "sin la menor demora una razón individual de todos ellos con expresión del nombre del regimiento, y del oficial, fecha su despacho, por quien es librado, lugar de su residencia, y si es Hacendado en el territorio está formado dicho su regimiento" 85 .

En aquel espacio de tiempo, la oficialidad debía "quedar ejerciendo en el ínterin las funciones y cargos de sus respectivos empleos"86. Especial consideración tuvieron los oficiales de artillería, pues el Virrey solicitó que se formase una lista separada de estos. Se puede inferir la necesidad de tener un catastro completo sobre el arma de artillería, dada las ponderadas necesidades de defensa del litoral costero del Virreinato por la constante presencia de buques de guerra británicos.

\section{Conclusiones}

La movilización militar permanente efectuada a partir de 1788, a modo de medida preventiva contra las hostilidades de los buques de guerra de la Gran Bretaña, tuvo una importancia gravitante para la seguridad hemisférica en las costas del Virreinato del Perú. Es por tal motivo que la ciudad y puerto de Arica, en el ámbito militar, llegó a tener un mayor predominio que la ciudad de Arequipa, capital provincial de la Intendencia, debido a que sirvió como Comandancia General para la dirección de la ejecución del plan de defensa militar. La definición hecha por el intendente Álvarez y Jiménez sobre el principio rector del arte de la guerra, se ajusta al pensamiento militar ilustrado que se desarrolló durante el siglo XVIII, de lo cual se puede inferir que su formación militar estaba en concordancia con los últimos avances en lo que respecta a la estrategia militar, especialmente a partir de las reformas a las milicias iniciadas en la isla de Cuba.

En el ámbito de la estructura interna de la defensa, las milicias fueron el principal medio de protección que se empleó en las zonas costeras, lo que demuestra que en aquel periodo la elite local de la zona concentró un gran poder e incidencia política. Las reformas de las milicias de 1791 y 1792, que apuntaron a regular el sistema institucional de los oficiales de milicias locales, también tuvo, implícitamente, la intención de reducir la potencial amenaza que representaba el predominio del manejo de las armas por parte de los americanos, pues muchos continuaban

85 ANH, AAA, leg. 8, pieza 4, fs. 1v-2r.

86 ANH, AAA, leg. 8, pieza 4, f. 2r. 
indebidamente en sus cargos. Además, la negativa de los oficiales del Regimiento Real de Lima, y del mismo Intendente Álvarez y Jiménez, de aceptar la solicitud del subdelegado Menocal del empleo de soldados veteranos para instruir a las inexpertas milicias del partido, es una fuerte evidencia sobre la profunda ruptura social que existió entre españoles y americanos.

Aparte de los conflictos suscitados dentro de la estructura militar del partido de Arica, las continuas fricciones entre las autoridades civiles y militares, donde los intendentes, y principalmente los subdelegados de los partidos, estuvieron en una constante lucha contra la autoridad de los comandantes militares veteranos sobre el control y dirección de las operaciones militares. Es así, que, en vez de existir una normal jerarquía de la dirección militar de las provincias y sus partidos, en la que las autoridades políticas cumpliesen su rol de apoyo administrativo en lo militar, esta fricción se convirtió en la principal fuente de obstáculo que desarticuló la ejecución de las medidas de defensa. En lo político, terminó por establecer dos mandos administrativos contrapuestos, ya que la autoridad política provincial anulaba el actuar del comandante y viceversa.

En resumen, la principal amenaza para el sistema defensivo del partido de Arica, y en general para todo el Virreinato del Perú a fines del siglo XVIII, no fue sólo la vulnerabilidad del sistema defensivo en sí mismo, sino que fue fundamentalmente la propia estructura político-militar la que impidió la correcta aplicación de las reformas imperiales. La constante desconfianza hacia la sociedad americana, particularmente hacia las elites locales, hizo insostenible el funcionamiento óptimo de la defensa planificada por sus autoridades. El predominio de las preocupaciones políticas hacia el enemigo interior por sobre el enemigo exterior fue el causante del estado deplorable y de ineficiencia de la defensa militar del partido de Arica, y en general de toda la costa de la Intendencia de Arequipa.

Fecha de recepción: 17/09/20 


\section{Referencias Bibliográficas}

Anderson, M., "European Diplomatic Relations, 1763-1790”, en Goodwin, A., ed., The New Cambridge Modern History. Volume VIII, Cambridge University Press, London, 1976, 252-278.

Andrien, Kenneth y Kuethe, Allan, The Spanish Atlantic World in the Eighteen Century. War and The Bourbon Reforms, 1713-1796, Cambridge University Press, New York, 2014.

Calvo, Antonio, "Génesis del II Imperio Británico y Ocaso del Universalismo Español: La Doble Vertiente del Conflicto de Nootka (1790)", HISPANIA, Revista Española de Historia, LXVIII/228, 2008, 151-192.

Campbell, Leon, "The military reform in the viceroyalty of Peru, 1762-1800", A dissertation presented to the graduate council of the University of Florida, in partial fulfillment of the requirements for the degree of doctor of philosophy, University of Florida, 1970.

Campbell, Leon, "After the Fall: The Reformation of the Army of Peru, 1784-1816", Iberoamerikanisches Archiv, 4/1, 1977, 1-28.

Choque, Carlos y Muñoz, Iván, "El Camino Real de la Plata. Circulación de mercancías e interacciones culturales en los valles y Altos de Arica (Siglos XVI al XVIII)", Revista Historia, Santiago, 49/I, 2016, 57-86.

Choque, Carlos, Anttonio Álvarez y Ximénez. La visita al partido de Arica, 1793, Ediciones Universidad de Tarapacá, 2018.

Dagnino, Vicente, El corregimiento de Arica, Imprenta La Época, Arica, 1909.

D’Wartelet, J., Diccionario Militar, Imprenta de D. Luis Palacios, Madrid, 1863.

Galdames, Luis et al., Historia de Arica, Editorial Renacimiento, Santiago, 1981.

Garate, María, "Las reflexiones militares del Marques de Santa Cruz de Marcenado", Revista de Historia Militar, Madrid, XXIX/núm. Especial, 1985, 21-48.

Gómez, Carmen, El sistema defensivo americano. Siglo XVIII, Editorial MAPFRE, Madrid, 1992.

Kuethe, Allan, "La crisis naval en tiempos de Carlos IV", Boletín de la Real Academia Sevillana de Buenas Letras: Minervae Baeticae, 42, 2014, 269-281.

Lafuente, Modesto, Historia General de España. Tomo decimoquinto, Montaner y Simon Editores, Barcelona, 1889.

Marchena, Juan. "El ejército de América y la descomposición del orden colonial. La otra mirada en un conflicto de lealtades", Revista Militaria, Madrid, 4, 1992, 63-91.

Marqués de Santa Cruz de Marcenado, Reflexiones Militares. Tomo X, Juan Francisco Mairesse, Turín, 1727. 
Real Ordenanza para el establecimiento e instrucción de intendentes de exército y provincia en el Virreinato de Buenos Aires, Imprenta Real, Madrid, 1782.

Reglamento y aranceles reales para el comercio libre de España a Indias de 12 de octubre de 1778, Imprenta de Pedro Marín, Madrid, 1778.

Rosenblitt, Jaime, Centralidad geográfica, marginalidad política: La región de TacnaArica y su comercio, 1778-1841, DIBAM, Santiago, 2013.

Vaultier, Observaciones sobre el arte de hacer la Guerra, Imprenta de Pedro Marín, Madrid, 1773. 